\section{Retinal degeneration and transplantation in the Royal College of Surgeons rat}

R.D. LUND, J.M. LAWRENCE, M.P. VILLEGAS-PÉREZ,

T.M. LITCHFIELD, Y. SAUVE, S.J.O. WHITELEY, P.J. COFFEY

\begin{abstract}
The Royal College of Surgeons rat provides a valuable animal model for examining the ontogeny of inherited or acquired photoreceptor degeneration and for assessing various treatment paradigms. Here we describe a sequence of events in which photoreceptor loss induces secondary changes that ultimately result in a progressive loss of retinal ganglion cells. The functional consequences of photoreceptor loss are described and compared with those observed in dystrophic animals that received grafts of pigment epithelial cells at an early stage in the degenerative process. The results of this work suggest that transplantation might slow or halt the progress of photoreceptor loss in certain human retinal degenerative conditions, provided suitable safeguards have been put in place.
\end{abstract}

Key words RCS rat, Retinal degeneration, Retinal pigment epithelium, Transplantation, Visual function

Transplantation involving the retina has a long history; one of the earliest reports of eye transplantation in a human comes from $1887 .{ }^{1}$ The technique assumed a central role in experimental biology some 60 years later in the series of studies on Amphibia, begun by Sperry ${ }^{2}$ and subsequently developed by Gaze and others. ${ }^{3}$ They took advantage of the fact that the optic nerve of these animals is capable of regeneration; and they were able to show that central patterns of connectivity were maintained even after various graft translocations. From this, mechanisms that determined neural specificity were identified.

Similar studies had not been undertaken in mammals, but an experiment in which lesions were made in rodent brains in utero ${ }^{4}$ suggested that transplantation of the rodent visual system during development might provide insights into the substrates of neural specificity in the mammalian brain. ${ }^{5}$ As these studies evolved, we were able to show that fetal retinae, implanted to neonatal rat brains, differentiated much of the normal structure of a retina. In addition ganglion cells in the transplants sent bundles of axons into the host brain, which sought out appropriate visual centres in the brainstem where they formed connections. ${ }^{6}$ The efficacy of these connections could be assayed by a series of simple functional tests. ${ }^{7}$

Physiological responses were recorded from the superior colliculus, where unit activity was elicited to transplant illumination. ${ }^{8}$ The pattern of light-driven activity was similar to that seen in the normal superior colliculus. ${ }^{9}$ Furthermore, illumination of the transplant resulted in constriction of the host eye's pupil, the amplitude of the response correlating with the intensity of light. ${ }^{10,11}$ Photic stimuli could also be used to elicit conditioned suppression and photophobic responses. ${ }^{12}$

The success with which our transplants integrated with immature host brains led us to examine how well they might integrate functionally after implantation into adult rat brains. These transplants were also capable of forming specific connections and mediating appropriate responses to light, ${ }^{13,14}$ but they did not differentiate as well as those in neonatal hosts. Their axons grew for shorter distances and, while behavioural responses mediated through the transplants could be elicited, the success rate was lower in adult host. This reduced efficacy might be due to the enhanced inflammatory and reactive responses of the mature brain ${ }^{15}$ as well as to the less permissive environment for axon outgrowth resulting from the maturation of the glial cell population. ${ }^{16}$ In addition, it became clear that although there was an element of immune privilege afforded to grafts in the central nervous system, protection was not absolute and grafts were always susceptible to rejection. ${ }^{17}$

In summary these observations showed that the axons of implanted retinal cells were capable of seeking out appropriate postsynaptic targets in the brain and that these reconstructed circuits were capable of relaying appropriate and sensible information sufficient to effect host visual responses. However, this process was
R.D. Lund

J.M. Lawrence

T.M. Litchfield

Y. Sauvé

S.J.O. Whiteley

Department of Pathology Institute of Ophthalmology

11-43 Bath Street

London EC1V 9EL, UK

M.P. Villegas-Peréz Laboratorio Oftalmologia

Experimental

Facultad de Medicina Universitad de Murcia

30.100 Espinardo

Murcia, Spain

P.J. Coffey

Department of Psychology

University of Sheffield

Sheffield, UK

Our work has primarily been funded by the Medical Research Council (UK), Foundation Fighting Blindness (USA) and Action Research (UK) 

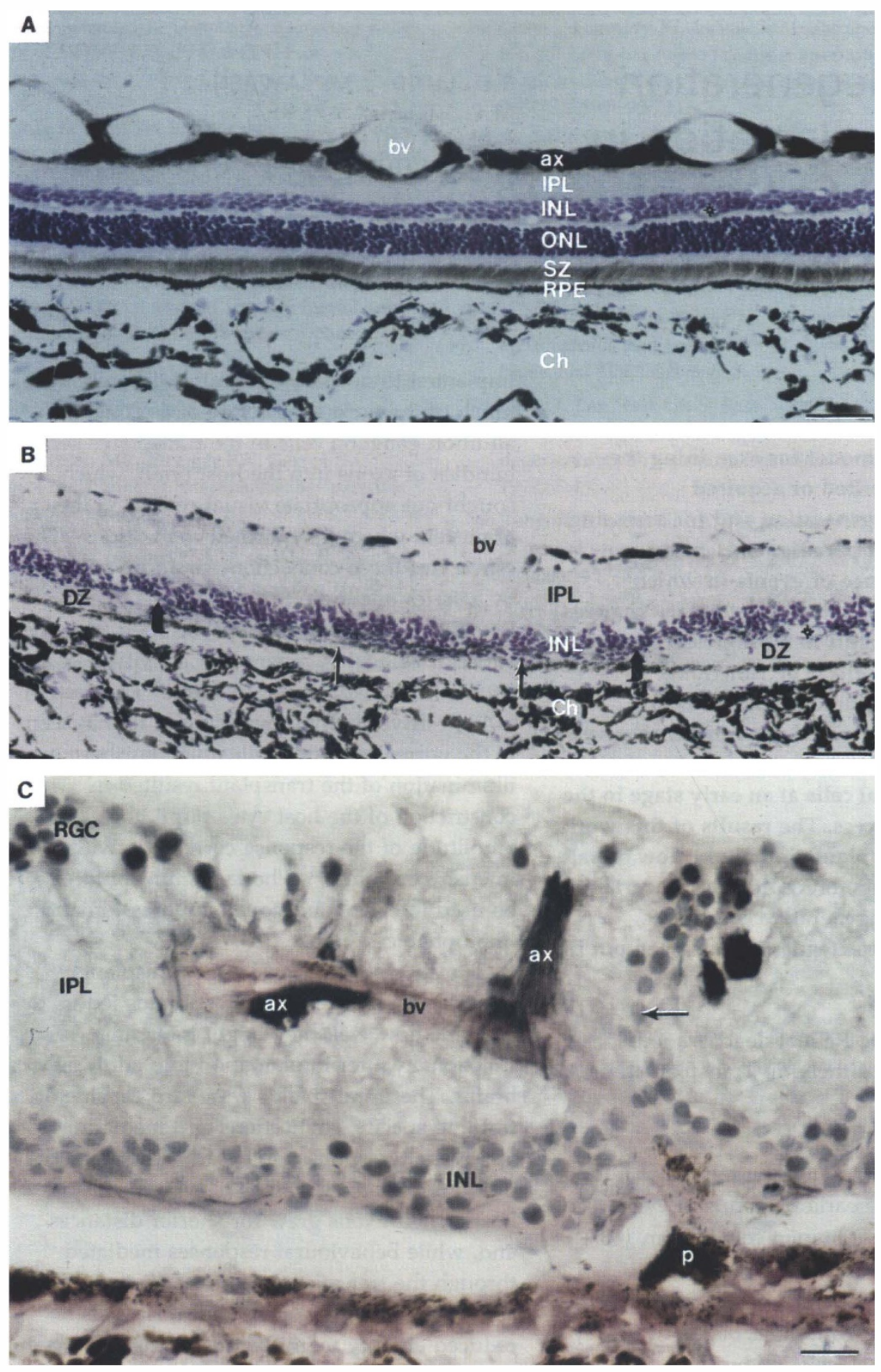

Fig. 1. Light micrographs of vascular and cellular changes occurring in the non-dystrophic Royal College of Surgeons' $(R C S)$ rat retina $(A)$ and dystrophic rat retina $(B, C)$. (A) The normal retinal layers at a point close to the optic disc. ax, axons from retinal ganglion cells (RGCs); IPL, inner plexiform layer; INL, inner nuclear layer; ONL, outer nuclear layer; $S Z$, inner and outer segment zones; RPE, retinal pigment epithelium; Ch, the choroid layer outside the retina. Blood vessels (bv) normally cross the inner retinal surface and extend into the more superficial retinal layers, but only as far as the junction of the inner nuclear layer with the outer plexiform layer (e.g. asterisk). RGC axons are confined to the inner surface of the retina. Four-month-old animal. (B) A dystrophic retina at 4 months of age. The ONL and SZ have degenerated but a debris zone $(D Z)$ remains. At some points (for instance, region between the dark curved arrows) INL cells and the RPE are juxtaposed. Some RPE cells appear devoid of pigment (layer of cells indicated between small arrows). RGC axons are still confined to the inner surface of the retina. $(A)$ and (B) have been reacted with RT97 and counterstained with thionin. (C) RGC axon bundles encasing a blood vessel (bv) and pigment spicules ( $p$ ) in cells migrating along the same vessel. A column of cells (arrow, presumably from INL) can be seen crossing the IPL. Fourteen-month-old dystrophic retina, treated with $R T 97$ and DAB (for axons) plus RECA antibody and alkaline phosphatase (for endothelial cells). Scale bars in $(A)$ and $(B)$ represent $50 \mu \mathrm{m}$; scale bar in (C) represents $20 \mu \mathrm{m}$. 
compromised to some extent in adult hosts by the reactive events occurring in the central nervous system in response to damage.

The ability of transplants to restore lost visual function in experimental animals raised the possibility that cell transplantation to the eye might also be effective in limiting the progress of photoreceptor death in a range of retinal degenerative diseases. This approach has been pursued by several groups. ${ }^{18-30}$ A number of different animal models have been studied, but the Royal College of Surgeons (RCS) rat, first described in the 1930s, ${ }^{31}$ has been one of the most widely studied. This animal manifests a progressive degeneration of photoreceptors, which begins during the first month of life, is rapid over the next 2 months, ${ }^{32}$ but then continues slowly for more than a year. ${ }^{33}$ The photoreceptor loss (Fig. 1B, compared with the age-matched non-dystrophic control shown in Fig. 1A) is caused by a retinal pigment epithelial (RPE) cell defect, and as such represents an indirect form of retinitis pigmentosa (RP), in which photoreceptor degeneration results from a defect involving extraneous events. ${ }^{34}$ In addition there are similarities with agerelated macular degeneration (ARMD), ${ }^{35,36}$ which may also occur as a result of RPE dysfunction. ${ }^{37}$

Transplantation of healthy RPE during the first month of life delays or prevents the degenerative process in the RCS rat retina. ${ }^{38}$

We have concentrated on three specific questions relating to transplant efficacy, using the RCS rat model. Firstly, does the loss of photoreceptors result in changes in the inner retina? Secondly, how would visual function be compromised by the progressive photoreceptor loss? Thirdly, how might transplantation modulate or limit functional deterioration?

\section{Results}

\section{Effect of photoreceptor loss on the inner retina}

The first question addressed was whether loss of photoreceptors would affect the integrity of the inner retina and central visual pathways. There are numerous instances of secondary effects of degeneration - for example the transneuronal atrophy seen in neurons of the primate lateral geniculate nucleus after optic nerve damage. ${ }^{39,40}$ Similar events occurring in the inner retina after photoreceptor loss would limit the efficacy of transplants to protect photoreceptors from damage. Inner retinal changes, including the loss of retinal ganglion cells (RGCs) or their axons ${ }^{41,42}$ have been observed in humans with RP and the normal laminar order of the retina is severely disrupted in patients at an advanced stage of the disease. ${ }^{43}$ The cause of these changes is not known. Is it due to transneuronal atrophy or to some other event?

Earlier studies on the RCS rat suggested that the only neural deficit to be seen was a loss of photoreceptors, ${ }^{32,33,44,45}$ but recent anatomical studies have shown that changes could also be detected in the inner retina. Kohler et al. ${ }^{46}$ have reported degenerative changes involving bipolar and dopamine-containing amacrine cells. $\mathrm{We}^{47,48}$ have discovered that there is progressive RGC loss that appears to be secondary to the vascular abnormalities described by others. ${ }^{49-51}$ In time these lead to a massive disruption of the inner retina, loss of RGCs and hence loss of the output from the eye to the brain. A sequence of changes can be defined. First, as the photoreceptor layer is lost, small groups of inner nuclear layer cells and the RPE cell layer become juxtaposed and adhesions form with Bruch's membrane. These regions may be the sites where neovascular formations develop in relation to the RPE, supplied by vessels arising from the inner retinal circulation (Fig. 1B). The vessels provide conduits for the migration of RPE cells and inner nuclear cells into the inner retinal layers (Fig. 1C). These vessels, originating from the vitreal circulation, appear to be 'dragged' into the retina (Fig. 1C). This is particularly evident for circumferential vessels originating from the radial vascular trunks, especially ones close to the optic disc. As a consequence, optic axon bundles that run over these vessels are pulled into the retina (Fig. 1C). At the points of tension, the axons show evidence of damage, such as retraction bulbs and abortive sprouting.

Retrograde labelling reveals that whole segments of the retina are devoid of ganglion cells. This is a progressive event, becoming apparent at 6 months of age and continuing at a variable rate for at least 1.5 years, by which time ganglion cells are lost from as much as half the retina.

A mechanism whereby the ganglion cell loss occurs is suggested as follows: the network of vessels running through the retina becomes contractile, either because of smooth muscle covering arterioles or because contractility is conferred by migrating RPE cells (which have contractile cytoskeleton ${ }^{52,53}$ ). Because of the aberrant connection of the vitreal retinal circulation with the neovascular elements, contraction will pull any overlying axon bundles into the retina, causing them to be ligated. Since the effect is particularly prevalent close to the optic disc, a single invaginated vessel will affect a whole wedge-shaped area of RGCs. RPE cell transplants may limit the degree of neovascularisation, ${ }^{54,55}$ perhaps locally reducing damage to ganglion cell axons, but the protective effect afforded by distantly placed grafts may not extend to the optic disc.

Besides these pathological events, there are also metabolic and functional changes in the inner retina of RCS rats and these have an impact on the central nervous system. Immunohistochemistry shows elevated calbindin levels in the inner nuclear layer. ${ }^{56}$ Horizontal cells in the peripheral retina, stained with calbindin, appear swollen with larger processes. This change in the morphology of horizontal cells coincides with regions of high levels of receptor debris. Furthermore, there is an increase in expression of parvalbumin, apparently by AII amacrine cells within the inner nuclear layer. 


\section{Functional consequences of retinal degeneration}

It would be expected that the gradual loss of photoreceptors should lead to deterioration of visual function, but the extent to which the relation between the two is linear is a matter of considerable interest. This is an important issue to explore, since the central nervous system is very effective, even under normal conditions, at translating an imperfect signal into a coherent image. Under the abnormal circumstances created by a progressive reduction in sensory signal (for example, resulting from photoreceptor degeneration), there may well be central regulatory events compensating for the signal deficit. This compensatory mechanism has received little attention, but its contribution must be assessed so that repair strategies, such as transplantation, can be accurately evaluated.

By 60 days of age the electroretinogram (ERG) response of the RCS rat can no longer be recorded, ${ }^{32,57}$ even though photoreceptor loss is still at an early stage. There is also a progressive visual field deficit that can be measured by recording responses to small spots of light presented in a systematic fashion across the visual field. ${ }^{58}$ At about $40-45$ days of age, at a time when the retinal degeneration is at an early stage, there is a loss of response to focal stimulation presented at mesopic illumination intensities. This is first seen close to the optic disc, even though the photoreceptor layer is still at least half normal thickness. At higher light intensities a response can still be elicited from these partial scotomas, although with increased latency. The partial scotoma increases progressively in size with age until about 200 days, when it is rare to find any region of the colliculus that can respond to focal stimulation. Responses to whole-field illumination are lost by 300 days. A number of subcortically mediated functions, such as a conditioned suppression response ${ }^{12}$ and pupilloconstriction, ${ }^{59,60}$ persist for more than a year, albeit with reduced sensitivity. Abnormal parameters in the pupillary response are most evident at lower light levels and the threshold increases with age.

A reduction in sensitivity to illumination can likewise be seen in an animal's photophobic response. ${ }^{61}$ Typically, rats will avoid brightly illuminated areas in an unevenly lit arena and seek out the darker regions. This photophobic response is reduced in the RCS rat at 3 months of age, and decreases further by 6 months.

Orienting responses are also affected in RCS rats. When an object is brought into the visual field of a normal rat, the animal will turn towards that object. This response is subcortically mediated through the superior colliculus. By 3 months of age RCS rats fail to orient towards a visual stimulus regardless of whereabouts in the visual field the stimulus is presented (upper, lower, nasal or temporal). ${ }^{61}$

In a test of visual acuity, which is a cortically mediated behaviour, RCS rats are unable to distinguish between a neutral density filter and a 0.045 cycles/deg square-wave grating even at 3 months of age. Similarly, by the same age, RCS rats have difficulty in discriminating between a chequered pattern and an even pattern at the same illumination. ${ }^{61}$

It is clear, therefore, that different visual behaviours deteriorate at different rates: in general those behaviours, such as acuity responses, that require a higher order of analysis are lost earlier while simple reflexes, such as pupilloconstriction, persist for long periods, albeit with reduced amplitude. This suggests that simple functions can adjust to input losses more successfully than complex ones. Furthermore, as might be expected with a condition in which the primary effect is on rods, the defects are most evident at low light intensities.

Besides the progressive deterioration in vision associated with the photoreceptor loss, there is also indication of increased responsiveness in dystrophic RCS rats. Previous work has demonstrated an increased spontaneous activity, recorded from ganglion cells of the retina ${ }^{62}$ and from the superior colliculus. ${ }^{63}$ Increased responsiveness in the superior colliculus most likely reflects retinal events. Studies on the activation of the immediate early gene, c-fos, in the superior colliculus have produced some unexpected results. ${ }^{64,65}$ In normal rats maintained in the dark there are very few cells expressing c-fos in the upper layers of the colliculus. If one eye is subjected to a flashing light for $30 \mathrm{~min}$ before fixation, the numbers of c-fos-positive cells increase dramatically in the colliculus contralateral to the stimulated eye. Bilateral stimulation causes elevated levels in both colliculi.

In the RCS rat, even at 7 months of age when the photoreceptor layer is reduced to a single discontinuous layer, light stimulation shows activated cell numbers similar to those in normal rats after illumination. A reduced response is only seen at around 12 months of age when anatomically it is very difficult to identify any photoreceptors at all. In the dark-maintained animals a very different pattern is seen in which the numbers of c-fos-labelled cells exceed those obtained after light stimulation. In accord with this, the colliculus contralateral to the unstimulated eye, under conditions of unilateral stimulation, has more c-fos cells than the one driven by the illuminated eye. The elevated dark levels are abolished by optic nerve section, indicating that they reflect changes in intraretinal processing. The lightdriven activity may reflect the functioning of remaining cones; as such the similarity between RCS and normals is perhaps not surprising. The deterioration with time presumably reflects secondary cone loss and/or ganglion cell loss. The abnormal dark activity possibly results from a disruption or imbalance in the complex and highly labile circuitry whereby the rod input is relayed through the retina to the ganglion cells. ${ }^{66}$ What is surprising is that c-fos expression usually occurs in response to change rather than steady-state activity, suggesting that there is perhaps some cyclic activity occurring in the retinae of these animals. These observations may have important implications for transplantation studies, since reversing the 
photoreceptor loss may unbalance the exaggerated dark response, and in so doing compromise the expected level of recovery.

\section{Functional consequences of transplantation}

The loss of photoreceptors in RCS rats can be limited by transplanting freshly isolated non-dystrophic RPE cells into the subretinal space of dystrophic animals during the first month of life, before the degenerative process has progressed too far. ${ }^{38}$ The functional impact of such transplantation has been assayed using several of the evaluation methods described above. The first to be used was the ERG, which showed that the response could be partially preserved by transplantation. ${ }^{67}$ The pupilloconstrictor response is a particularly sensitive test, which not only showed the beneficial effects of the grafts but also revealed that sham effects could persist for as long as 6 months. ${ }^{38}$ Discriminating transplantrelated recovery from secondary events related to surgical intervention alone requires careful quantitative analysis, but if this is done, significant changes can be seen in latency of response onset after grafting, while amplitude shows a trend towards improvement. The most dramatic changes can be discerned using low light intensities.

Visual field responses cannot normally be recorded from the superior colliculus of the RCS rat beyond 6 months of age. After transplantation, however, a localised area of preservation of visual fields could be defined that corresponded approximately in position to the area in which the transplant was located ${ }^{60} \mathrm{Within}$ these regions the latency of response onset was closer to normal values.

Pattern recognition after RPE grafting to RCS rats also showed improvement. Rats with transplants were able to distinguish between a highly patterned environment and a non-patterned environment. This was shown by significantly increased activity when the animals were placed in a patterned box; control dystrophic RCS rats showed no change in activity and effectively appeared blind. $^{61}$

\section{Use of different donor cell populations}

The problems involved in collecting freshly isolated cells has prompted the search for alternative methods of storing material or alternative sources of cells. Photoreceptor preservation can be achieved by immersing retinae in Optisol-GS medium and storing at $4{ }^{\circ} \mathrm{C}$ for several days prior to dissociation and transplantation; ${ }^{68}$ and RPE cells have been cryopreserved and then used for grafting. ${ }^{69}$ It appears too that pigmented cells taken from the iris can also take on the role of RPE cells. ${ }^{70}$ However, RPE cells that are allowed to continue dividing in culture become less effective in supporting photoreceptor survival in RCS rats. ${ }^{71}$ An alternative approach we have explored is the use of an immortalised RPE cell line. RCS rats with such transplants show good photoreceptor rescue and a considerable functional improvement on a variety of tests. $^{72-74}$ The pupillary light reflex, the area of visual field rescued and performance on tests for pattern vision are all much better than in controls and, on average, superior to those in rats that had received freshly isolated RPE cells.

\section{Discussion}

\section{General comments on experimental studies}

The defect in the RCS rat is associated with the RPE cell. While no human homologue has yet been identified, the closest comparison would appear to be with 'indirect' forms of RP, in which photoreceptor loss is caused by events external to the photoreceptor cells themselves. Diseases such as Sorsby's fundus dystrophy, caused by a defect in TIMP-3, are included in this category. ${ }^{75}$ In addition, photoreceptor degeneration occurs secondary to RPE disruption in conditions such as ARMD and, on this basis, transplantation of healthy RPE cells to patients with this disease has already been attempted, although with little evidence of success. ${ }^{76}$ It would appear, therefore, that the RCS rat may serve as a useful animal model for studying the progress of photoreceptor degeneration and its central visual consequences in a range of human retinal dystrophies. In addition, transplantation methodologies can be assessed.

The studies described here show the RPE defect in the RCS rat affects not only rod photoreceptor viability, but also the integrity of the inner retina and central visual pathways. The loss of RGCs, initiated after the formation of aberrant connections between inner retinal vessels and new vessels in the subretinal space, provides an example of how indirect second-order events can be. While some visual functions deteriorate in register with the phase of rapid photoreceptor loss, others are preserved for long periods. This can in part be attributed to the fact that the primary photoreceptors lost are rods, cone degeneration being a much later event. In addition, there are changes in neural activity in the retina that may play some part in altering efficiency of performance of those circuits processing information from the gradually diminishing rod signal.

The work described here shows that RPE cells, introduced into the subretinal space of dystrophic RCS rats at an early stage in the degenerative process, can promote functional and anatomical rescue. The functional recovery occurs over a range of visual behaviours, from simple reflex responses to complex discriminations. This satisfies the requirement that transplants should be capable of preserving at least some visual function that would otherwise be lost as a result of an inherited dystrophy. It is not yet established whether grafted photoreceptors, under similar conditions, can restore vision. 


\section{Application of transplantation to humans}

When exploring whether transplantation into the retina could serve as a clinical tool for the amelioration of various degenerative diseases, it is clear from the attempts made so far that this is not a simple undertaking. While animal studies are beginning to show that grafts can maintain some level of vision after early intervention, they have yet to show that lost photoreceptors can be replaced and their function recovered. The continued development of animal studies, coupled with the first clinical experiments, highlights a number of issues that must be addressed before transplantation could be considered as a routine therapy. The principal ones are outlined below:

1. Immune rejection of grafts. This has already been suggested as a factor in the course of response to RPE cell transplantation in humans, although there are indications that it may be less important in the case of photoreceptor grafts. While there is some level of immune privilege in the normal subretinal space, the mechanism is not well understood and it is not known whether it would apply in the dystrophic retina.

2. Transplant technology. The majority of experimental work has been undertaken in rodents. The technology involved does not always translate easily to the large human eye and there are still many questions to be answered relating to the best methods for preparing cells for transplantation and for delivering them into the eye.

3. Safety. Freshly harvested cells must be rigorously tested for a variety of potential infective agents Cell lines could be more easily screened but they must not in themselves induce any aberrant cell reactions or growth patterns.

4. Stage at which a transplant should be performed. Given the potential for second-order degeneration and deterioration of extraretinal membranes and tissue with time, it is likely that the efficacy of grafts transplanted at a more advanced disease stage could be compromised. Transplantation at an early stage of disease progression may put a functioning eye at risk.

5. Assessment. Providing careful and secure objective measures of visual function before and after transplantation is fraught with difficulties. It is particularly important that these should be available for assessing clinical trials, since the desire for improvement may exaggerate any real effects.

\section{Summary}

Experimental studies are beginning to show that transplantation of cells to the subretinal space can reverse the effects of hereditary retinal disease in animals and have encouraged the expansion of such investigations to humans.

The cautions raised in the above discussion do not invalidate the use of transplantation. What they do emphasise is that a great deal more investigative work must be undertaken. The fact that retinal degenerative diseases are not in themselves life threatening argues for caution in the momentum of patient research. Nevertheless, a successful clinical therapy could emerge given an appropriately paced and systematic approach.

We wish to thank our colleagues Manuel Vidal-Sanz, Anthony Vugler and Len Hetherington, who have made major contributions to the research described

\section{References}

1. May $\mathrm{CH}$. Transplantation of a rabbit's eye into the human orbit. Arch Ophthalmol 1887;16:47-53.

2. Sperry RW. Chemoaffinity in the orderly growth of nerve fiber patterns of connection. Proc Natl Acad Sci USA 1963;50:703-10.

3. Gaze RM, Keating MJ. Further studies on the restoration of the contralateral retinotectal projection following regeneration of the optic nerve in the frog. Brain Res 1970;21:183-207.

4. Miller BF, Lund RD. The pattern of retinotectal connections in albino rats can be modified by fetal surgery. Brain Res 1975;91:119-25.

5. Lund RD, Hauschka SD. Transplanted neural tissue develops connections with host rat brain. Science 1976;193:582-4.

6. Lund RD, Radel RD, Horsburgh GM. Intracerebral transplantation of mammalian retina. In: Cronly-Dillon JR, editor. Vision and visual dysfunction, vol 2. Development and plasticity of the visual system. Basingstoke: Macmillan, 1991:314-34.

7. Coffey PJ, Lund RD, Rawlins JNP. Detecting the world through a retinal implant. Prog Brain Res 1990;82:269-76.

8. Simons DJ, Lund RD. Fetal retinae transplanted over tecta of neonatal rats respond to light and evoke patterned neuronal discharges in the host superior colliculus. Dev Brain Res 1985;21:156-9.

9. Fukuda Y, Iwama K. Visual receptive field properties of single cells in the rat superior colliculus. Jpn J Physiol 1978;28:385-400.

10. Radel JD, Kustra DJ, Das S, Elton S, Lund RD. The pupillary light response: assessment of function mediated by intracranial retinal transplants. Neuroscience 1995;68:909-24.

11. Radel JD, Kustra DJ, Lund RD. The pupillary light response: functional and anatomical interaction among inputs to the pretectum from transplanted retinae and host eyes. Neuroscience 1995;68:893-908.

12. Coffey PJ, Lund RD, Rawlins JNP. Retinal transplantmediated learning in a conditioned suppression task in rats. Proc Natl Acad Sci USA 1989;86:7248-9.

13. McLoon SC, Lund RD. Development of fetal retina, tectum and cortex transplanted to the superior colliculus of adult rats. J Comp Neurol 1983;217:376-89.

14. Klassen H, Lund RD. Retinal graft-mediated pupillary responses in rats: restoration of a reflex function in the mature mammalian brain. J Neurosci 1990;10:578-87.

15. McKeon RJ, Schreiber RC, Rudge JS, Silver J. Reduction of neurite outgrowth in a model of glial scarring following CNS injury is correlated with the expression of inhibitory molecules on reactive astrocytes. J Neurosci 1991;11:3398-411.

16. Schwab ME, Kapfhammer JP, Bandtlow CE. Inhibitors of neurite outgrowth. Annu Rev Neurosci 1993;16:565-95.

17. Pollack IF, Lund RD. Blood-brain barrier protects foreign antigens in the brain from attack. Exp Neurol 1990;108:114-21.

18. Turner JE, Blair JR. Newborn rat retinal cells transplanted into a retinal lesion site in adult host eyes. Dev Brain Res 1986;26:91-104.

19. Li L, Turner JE. Inherited retinal dystrophy in the RCS rat: prevention of photoreceptor degeneration by pigment epithelial cell transplantation. Exp Eye Res 1988;47:911-7. 
20. Li L, Sheedlo HJ, Gaur V, Turner JE. Effects of macrophage and retinal pigment epithelial cell transplants on photoreceptor cell rescue in RCS rats. Curr Eye Res 1991;10:947-58.

21. Gouras P, Du J, Kjeldbye H, Yamamoto S, Zack DJ. Reconstruction of degenerate $r d$ mouse retina by transplantation of transgenic photoreceptors. Invest Ophthalmol Vis Sci 1992;33:2579-86.

22. Gouras P, Du J, Kjeldbye H, Yamamoto S, Zack DJ. Longterm photoreceptor transplants in dystrophic and normal mouse retina. Invest Ophthalmol Vis Sci 1994;35:3145-53.

23. Lopez R, Gouras P, Kjeldbye H, Sullivan B, Repucci V, Britis M, Wapner F, Goluboff E. Transplanted retinal pigment epithelium modifies the retinal degeneration in the RCS rat. Invest Ophthalmol Vis Sci 1989;30:586-8.

24. Yamamoto S, Du J, Gouras P, Kjeldbye H. Retinal pigment epithelium transplants and retinal function in RCS rats. Invest Ophthalmol Vis Sci 1993;34:3068-75.

25. del Cerro M, Gash DM, Rao GN, Notter MF, Wiegand MF, Wiegand SJ, del Cerro C. Intraocular retinal transplants. Invest Ophthalmol Vis Sci 1985;26:1182-5.

26. del Cerro M, Gash DM, Notter MF, Wiegand SJ, Jiang LQ, del Cerro C. Transplants of retinal cells into the normal and damaged retina of genetically dissimilar adult hosts. Soc Neurosci Abstr 1986;15:501.

27. Silverman MS, Hughes SE. Transplantation of photoreceptors to light damaged retina. Invest Ophthalmol Vis Sci 1989:30:1684-90.

28. Silverman MS, Hughes SE. Light dependent activation of light damaged retina by transplanted photoreceptors. Invest Ophthalmol Vis Sci 1989;30(Suppl):205.

29. Silverman M, Hughes S, Valentino T, Liu Y. Photoreceptor transplantation: anatomic, electrophysiologic, and behavioural evidence for the functional reconstruction of retinas lacking photoreceptors. Exp Neurol 1992;115:87-94.

30. Ehinger B, Bergstrom A, Seiler M, Aramant RB, Zucker CL, Gustavii B, Adolph AR. Ultrastructure of human retinal cell transplants with long survival times in rats. Exp Eye Res 1991;53:447-60.

31. Bourne MC, Campbell DA, Tansley K. Hereditary degeneration of the rat retina. $\mathrm{Br} \mathrm{J}$ Ophthalmol 1938;22:613-23

32. Dowling JE, Sidman RL. Inherited retinal dystrophy in the rat. J Cell Biol 1962;14:73-109.

33. LaVail MM, Batelle B-A. Influence of eye pigmentation and light deprivation on inherited retinal dystrophy in the rat Exp Eye Res 1975;21:167-92.

34. Milam AH, Li Z-Y. Retinal pathology in retinitis pigmentosa considerations for therapy. In: Anderson RE, LaVail MM, Hollyfield JG, editors. Degenerative diseases of the retina New York: Plenum Press, 1995:275-84.

35. Young RW. Pathophysiology of age-related macular degeneration. Surv Ophthalmol 1987;31:291-306.

36. Curcio CA, Medeiros NE, Millican CL. Photoreceptor loss in age-related macular degeneration. Invest Ophthalmol Vis Sci 1996;37:1236-49.

37. Bressler NM, Silva JC, Bressler SB, Fine SL, Green WD. Clinicopathologic correlation of drusen and retinal pigment epithelial abnormalities in age-related macular degeneration. Retina 1994;14:130-42.

38. Whiteley SJO, Litchfield TM, Coffey PJ, Lund RD. Improvement of the pupillary light reflex of Royal College of Surgeons rats following RPE cell grafts. Exp Neurol 1996;140:100-4.

39. Cook WH, Walker JH, Barr ML. A cytological study of transneuronal atrophy in the cat and rabbit. J Comp Neurol 1951;94:267-91.

40. Hubel DH, Wiesel TN, LeVay S. Plasticity of ocular dominance columns in the monkey striate cortex. Phil Trans R Soc Lond (Biol) 1977;278:377-409.
41. Newman NM, Stevens RA, Heckenlively JR. Nerve fibre layer loss in diseases of the outer retinal layer. $\mathrm{Br} \mathrm{J}$ Ophthalmol 1987;71:21-6.

42. Stone JL, Barlow WE, Humayun MS, de Juan E, Milam A. Morphometric analysis of macular photoreceptors and ganglion cells in retinas with retinitis pigmentosa. Arch Ophthalmol 1992;110:1634-9.

43. Li Z-Y, Possin DE, Milam AH. Histopathology of bone spicule pigmentation in retinitis pigmentosa. Ophthalmology 1995;102:805-16.

44. Eisenfeld AJ, LaVail MM, LaVail JH. Assessment of possible transneuronal changes in the retina of rats with inherited retinal dystrophy: cell size, number, synapses and axonal transport by retinal ganglion cells. J Comp Neurol 1984;223:22-34

45. LaVail MM. Analysis of neurological mutants with inherited retinal degeneration. Invest Ophthalmol Vis Sci 1981;21:167-92.

46. Kohler K, Hartmann J, Fischer S, Zrenner E. Degenerative processes in the inner retina of the RCS rat. Invest Ophthalmol Vis Sci 1997;38:173.

47. Villegas-Peréz MP, Vidal-Sanz M, Lund RD. Mechanism of retinal ganglion cell loss in inherited retinal dystrophy. Neuroreport 1996;7:1995-9.

48. Villegas-Peréz MP, Lawrence JM, Vidal-Sanz M, LaVail M, Lund RD. Ganglion cell loss in the RCS rat retina: a result of compression of axons by contracting intraretinal vessels linked to the pigment epithelium J Comp Neurol 1998;392:58-77.

49. El Hifnawi E. Pathomorphology of the retina and its vasculature in hereditary retinal dystrophy in RCS rats. In: Zrenner E, Krastel H, Goebel H-H, editors. Research in retinitis pigmentosa, vol 62 . Advances in the biosciences. Oxford: Pergamon Press, 1987:417-34.

50. Caldwell RB. Blood-retinal changes in the retinal pigment epithelium of RCS rats with inherited retinal degeneration. In: Hollyfield JG, Anderson RE, LaVail MM, editors. Degenerative retinal disorders: clinical and laboratory investigations. New York: Liss, 1987:333-47.

51. van Driel D, Provis JM, Billson FA. Morphology of intraretinal new vessels in the PETH rat. Graefes Arch Clin Exp Ophthalmol 1988;226:576-82.

52. Owaribe K. The cytoskeleton of retinal pigment epithelial cells. Prog Retinal Res 1988;8:23-49.

53. Fuchs $U$, Kivela $T$, Tarkkanen A. Cytoskeleton in normal and reactive human retinal pigment epithelial cells. Invest Ophthalmol Vis Sci 1991;32:3178-86.

54. Seaton AD, Turner JE. RPE transplants stabilize retinal vasculature and prevent neovascularization in the RCS rat. Invest Ophthalmol Vis Sci 1992;33:83-91.

55. Seaton AD, Sheedlo HJ, Turner JE. A primary role for RPE transplants in the inhibition and regression of neovascularization in the RCS rat. Invest Ophthalmol Vis Sci 1994;35:162-9.

56. Vugler AA, Lund RD, Coffey PJ. Expression of calcium binding proteins in the superior colliculus of dystrophic RCS rat. Invest Ophthalmol Vis Sci 1997;38:S103.

57. Bush RA, Hawks KV, Sieving PA. Preservation of inner retinal responses in the aged Royal College of Surgeons rat. Invest Ophthalmol Vis Sci 1995;36:2054-62.

58. Sauvé Y, Klassen H, Whiteley SJO, Litchfield TM, Lund RD Retinotopic analysis of response parameters in the superior colliculus of RCS rats following retinal pigment epithelial cell transplantation. Soc Neurosci Abstr 1996;22:1978.

59. Whiteley S, Young M, Coffey P, Lund R. Pupillary light reflex in RCS rats: age-related changes and comparisons with visual acuity. Neuroscience 1994;19:1418.

60. Whiteley S, Young MJ, Litchfield TM, Lund RD. Changes in pupillary light reflex with age in RCS rats and the effects of intraretinal transplantation of retinal pigment epithelium. Invest Ophthalmol Vis Sci 1994;35:1524. 
61. Lund RD, Coffey PJ, Sauvé Y, Lawrence JM. Intraretinal transplantation to prevent photoreceptor degeneration. Ophthalmic Res 1997;29:305-19.

62. Yamamoto S, Du J, Gouras P, Kjeldbye H. Retinal pigment epithelial transplants and retinal function in $R C S$ rats. Invest Ophthalmol Vis Sci 1993;34:3068-75.

63. Sauvé Y, Klassen H, Whiteley SJO, Lund RD. Age-dependent visual field loss in RCS rats and the relative benefits of subretinal over intravitreal transplantation. Neurology (in press).

64. Coffey PJ, Hetherington L, Bin L, Whiteley SJO, Litchfield TM, Lund RD. Detection of visual patterns and c-fos expression in retina and superior colliculus of dystrophic RCS rats following RPE transplants. Invest Ophthalmol Vis Sci 1996;37:S94.

65. Lu B, Coffey PJ, Lund RD. C-fos expression in retina and superior colliculus following light flashes. Invest Ophthalmol Vis Sci 1996;37:S1047.

66. Vaney DI. Patterns of neuronal coupling in the retina. Prog Ret Eye Res 1994;13:301-55.

67. Jiang LQ, Hamasaki D. Corneal electroretinogram function rescued by normal retinal pigment epithelial grafts in retinal degenerative Royal College of Surgeons rats. Invest Ophthalmol Vis Sci 1994;35:4300-9.

68. DiLoreto DA, del Cerro C, Lazar ES, Cox C, del Cerro M. Storage of human fetal retina in Optisol prior to subretinal transplantation. Cell Transplant 1996;5:553-61.
69. Durlu YK, Tamai M. Transplantation of retinal pigment epithelium using viable cryopreserved cells. Cell Transplant 1997;6:149-62.

70. Rezai KA, Kohen L, Heimann K, Weidemann P. Iris pigment epithelium transplants rescue photoreceptors in dystrophic RCS rats. Invest Ophthalmol Vis Sci 1996;37:446.

71. Sheedlo HJ, Li-L, Turner JE. Effects of RPE age and culture conditions on support of photoreceptor cell survival in transplanted RCS dystrophic rats. Exp Eye Res 1993;57:753-61.

72. Litchfield TM, Whiteley SJO, Greenwood J, Adamson P, Lund RD. Grafting SV40 transformed rat retinal epithelial cells to the sub-retinal space. Invest Ophthalmol Vis Sci 1996;37:S93.

73. Litchfield TM, Whiteley SJO, Sauvé Y, Coffey P, Lund RD. Fresh and transformed RPE cell grafts rescue visual function in the RCS rat. Invest Ophthalmol Vis Sci 1997;38:4390.

74. Whiteley SJO, Litchfield TM, Sauvé Y, Lund RD. Transformed retinal pigment epithelial cell transplants improve visual function at older ages in RCS rats. Invest Ophthalmol Vis Sci 1997;38:1206.

75. Apte SS, Matei MG, Olsen BR. Cloning of the cDNA encoding human tissue inhibitor of metalloproteinases (TIMP-3) and mapping of the TIMP-3 gene to chromosome 22. Genomics 1994;19:86-90.

76. Algvere PV, Berglin L, Gouras P, Sheng Y. Transplantation of fetal retinal pigment epithelium in age-related macular degeneration with foveal neovascularization. Graefes Arch Clin Exp Ophthalmol 1994;232:707-16. 